\title{
Boom and bust plagues Pakistan's universities
}

\section{A bold experiment to build scientific leadership comes crashing back to Earth.}

\section{BY GEOFF BRUMFIEL IN LONDON \& MASON INMAN IN KARACHI}

$\mathrm{B}$ etween political assassinations, transport strikes and campus protests that sometimes erupt in gunfire, research at the University of Karachi has often been a touchand-go affair. "You set up an experiment one day and the next day, you can't come in because everything is shut down," says Shahana Kazmi, a biologist and pro-vice chancellor at the university - Pakistan's largest higher-education institution.

Despite the problems, science has been flourishing in Karachi and other Pakistani cities, thanks to an unprecedented investment in the country's higher-education system between 2002 and 2008 (see 'Rollercoaster budget'). As funding increased more than fivefold in that time, new institutes focusing on proteomics and agricultural research sprouted, and the University of Karachi's natural sciences department rose from nowhere to 223 in the 2009 QS World University Rankings.

But the money has stopped abruptly, after political scandal, economic recession and devastating flooding throughout the country. With funding set to be slashed for the second year running, the entire system is teetering on the brink of collapse, says Javaid Laghari, chairman of Pakistan's Higher Education Commission. "If we cut any further, it will be suicidal," he says. Last week, 71 university vice-chancellors threatened to resign after Abdul Hafeez Shaikh, the nation's finance minister, refused to commit funding for the cash-strapped system and told universities that they would have to find other sources of support - a tall order in a country in which even a small increase in tuition fees, for example, can lead to debilitating student strikes.

\section{AGENERAL'SBLESSING}

The sudden funding crash has left supporters and critics arguing over the legacy of Pakistan's grand experiment. Architects of the boom say that the infusion of money transformed flagging universities, and point to the thousands of $\mathrm{PhDs}$ and research papers produced in the past decade. But opponents say that the numbers hide a debilitating tidal wave of waste and corruption that has caused as much harm as good.

The surge in higher-education investment occurred after the rise to power of General Pervez Musharraf in 1999, who as leader of the army had led a low-key coup d'état and installed himself as de facto president. Musharraf was a liberal progressive who hoped to modernize Pakistan. "It was a moment in Pakistani history that now seems so distant," says Adil Najam, an expert in international development at Boston University in Massachusetts.

With the economy booming in the early 2000s, Pakistani academics sensed an opportunity. Higher education had never had much popular support in the country, where literacy hovers at about $50 \%$, but in Musharraf they saw a champion. In a series of reports, Najam and

\section{ROLLERCOASTER BUDGET}

After a period of rapid investment to develop Pakistan's higher-education and research base, funding is falling sharply.

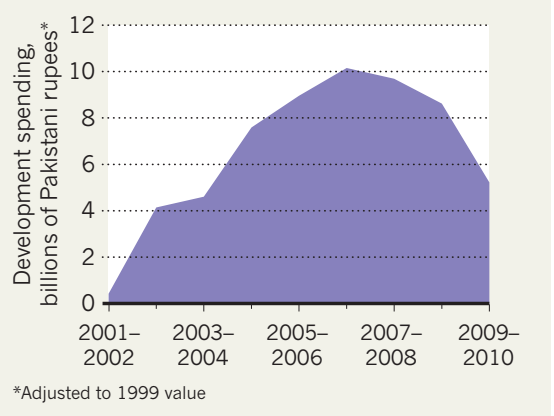

others made the case that if the nation could mobilize its universities, it could transform from a poor agricultural state into a knowledge economy (see Nature 461, 38-39; 2009). The group called for a new Higher Education Commission (HEC) to manage the investment, as well as better wages for professors, more grants for $\mathrm{PhD}$ students and a boost in research funding.

"One of the things about being a military dictator is that if you like an idea, you can do whatever you like with it," says Najam. Musharraf created the HEC and named Atta-urRahman, a close adviser, as its first chairman.

Rahman, a chemist at the University of Karachi and, at the time, the minister for science and technology, enthusiastically set out to overhaul the nation's universities. With Musharraf's support, annual research funding shot up $474 \%$ to 270 million rupees (US\$4.5 million in 2002) in the first year alone. The HEC set aside money for $\mathrm{PhD}$ students and created a tenure-track system that would give qualified professors a monthly salary of around US $\$ 1,000-4,000-$ excellent pay by Pakistani standards.

Rahman's strong scientific background, enthusiasm for reform and impressive ability to secure cash made him a hit at home and abroad. "It really was an anomaly that we had a person of that stature with that kind of backing," says Naveed Naqvi, a senior education economist at the World Bank, based in Islamabad. "Atta-ur-Rahman was a force of nature."

Between 2003 and 2009, Pakistan churned out about 3,000 PhDs, roughly the same number awarded throughout its previous 55-year history. More than 7,000 PhD students are now in training at home and abroad. Meanwhile, scientific research publications have soared from roughly 800 in 2002 to more than 4,000 in 2009 (see 'Publishing power').

But critics say that the numbers don't tell the entire story. Pervez Hoodbhoy, a physicist at Quaid-i-Azam University in Islamabad, was initially supportive of Rahman's plans, but grew increasingly sceptical. One day in 2005, he opened his newspaper to discover that his university had bought a particle accelerator. "I rubbed my eyes and said, 'This can't be true,"' says Hoodbhoy, who was head of the physics department at the time. The accelerator, an obscure device known as a pelletron, was ordered at the behest of other physicists at the university without a clear idea of how it would be used. "That machine has arrived, it's working perfectly, and for the last year and a half since it's been installed, it hasn't been used," he says.

The incident highlights how the flood of cash has led to profligacy, and ultimately to corruption, says Hoodbhoy, who is now one of the most outspoken critics of Rahman's plan. "I began to smell fish, and then it turned out there was a lot of fish." Among other problems, Hoodbhoy says that professors have enrolled PhD students simply for the cash stipends they can claim, that plagiarism has increased and that standards have dropped.

There is anecdotal evidence to support his claims. In 2007, the HEC cut off funding to the University of the Punjab in Lahore after administrators refused to take action against faculty members and students who were caught plagiarising. Salal Humair, a public-health scientist at 


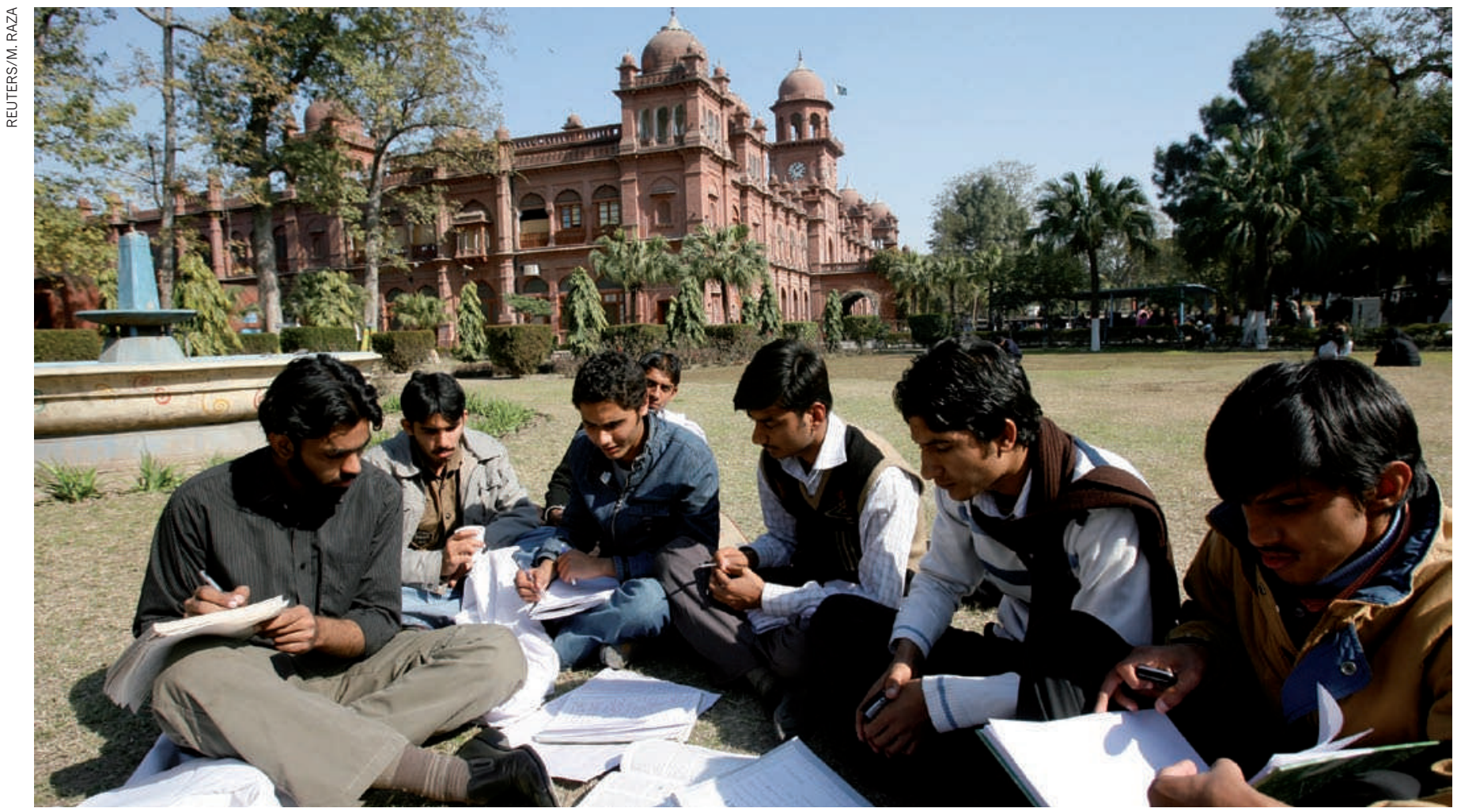

Students at the University of the Punjab in Lahore are among those facing an uncertain future.

the Lahore University of Management Sciences, a private university, says he has heard of many cases of professors enrolling PhD students for the money. "I think there was a lot of manipulation to try and get HEC funds," says Humair. The money "bred a culture of plagiarism and a culture of, I would say, incompetent PhDs".

\section{UNCERTAIN LEGACY}

Even the new tenure-track system, designed to boost funding for the best of Pakistan's academics, has shown signs of corruption. Irfan Chaudhry, an electrical engineer at the University of Engineering \& Technology in Lahore, who returned to Pakistan from the United States in 2008 on an HEC grant, says that he saw many professors playing the system. For example, says Chaudhry, a certain number of peer-reviewed publications are required to qualify for the tenure-track system. But many researchers "were publishing in completely random journals that were published in Lahore or somewhere like that. They definitely got around it."

"One can easily magnify such things and make it look like everything was being wasted," responds Rahman. He insists that most of the money has been spent responsibly, and that the investment has made a real difference to Pakistan's higher-education system.

The growth now seems to be over. At a new concrete building on the edge of the University of Karachi campus, net-walled greenhouses hold rows of mangrove seedlings, which might help to restore the ailing Indus River delta, says Ajmal Khan, a botanist overseeing the project.
"What we are doing could be of great benefit to the country," he says.

But just as the sprouts are poking through the soil, Khan's lab may be cut off. Since Musharraf was forced from office in 2008, the HEC has lost favour with the government. The recession has hit Pakistan hard, and last year the commission received only 11.3 billion rupees for new projects such as the plant lab. Adjusted for inflation, that is about half of what it got in the boom years of 2006-07. And Laghari says that repairing the damage caused by this summer's floods will cost the country billions of rupees. As the government looks to cut more cash from every part of the budget, the HEC is in the firing line.

To make matters more precarious, the HEC has become embroiled in a political scandal. A university degree is required to hold a seat in Pakistan's parliament, but this spring it emerged that many parliamentarians hold

\section{PUBLISHING POWER}

Pakistan's research publications have ballooned in recent years.

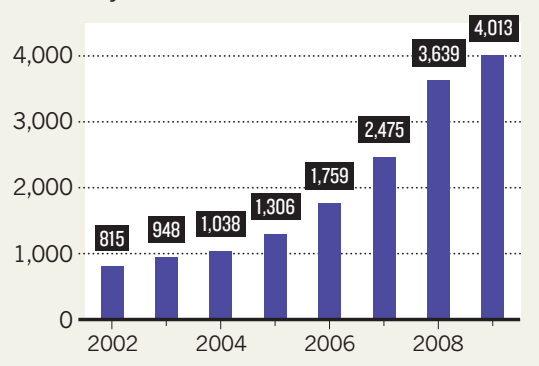

bogus certificates. By court order, the HEC has been verifying the degrees of more than a thousand elected officials nationwide. The process has so far revealed dozens of cheats and turned the commission into a political lightening rod. Laghari says that he has been targeted personally: his brother, Farooq, has been arrested and accused of corruption - falsely, says Laghari - as a result of the continuing investigation.

The upshot of the latest turmoil is that the HEC has received only $9 \%$ of the promised development funding for the 2010-11 financial year, half what it should have had by now. New projects are on hold until the situation improves, and Laghari says that he is scrambling to find alternative sources of funding, including a loan from the World Bank.

The uncertainty leaves the legacy of Pakistan's bold experiment up in the air. Rahman maintains that the progress made in the boom years means that a generation of new $\mathrm{PhDs}$ is about to return to the country to fulfil their promise. But if the cuts continue, "we are heading towards the stone age that existed before the Musharraf era", he warns. Sceptics such as Hoodbhoy, however, see the cuts as a coda to a misguided adventure that has actually lowered standards. "I don't think that the floods have anything to do with the fact that the higher education system is in terrible shape today," he says.

On the University of Karachi campus, Kazmi is worried that the new research institutes dotted around her campus may soon lie empty. "The building is there, the equipment is there, they've hired the faculty," she says. "Now there is no money." - SEE EDITORIAL P.367 